\title{
Effect of head position on the efficacy of topical treatment of chronic mucopurulent rhinosinusitis
}

\author{
R WILSON, D A SYKES, K L CHAN, P J COLE, I S MACKAY \\ From the Host Defence Unit, Department of Thoracic Medicine, Cardiothoracic Institute, and the Nose Clinic, \\ Brompton Hospital, London
}

Chronic mucopurulent rhinosinusitis is a common accompaniment of chronic or recurrent bronchial sepsis-for example, in patients with bronchiectasis and cystic fibrosis. It may be treated with systemic or topical medication, or both, but the response is often unsatisfactory. The efficacy of topical medication may depend on adequate exposure of the nasal and paranasal sinus mucosa to the chosen drug. ${ }^{12}$ We have studied 20 patients with chronic mucopurulent rhinosinusitis who were treated by betamethasone with neomycin nose drops (Betnesol N, Glaxo) administered either in the conventional head back (HB) position or in the head down and forwards (HDF) position. ${ }^{12}$ In this latter position the patient kneels with the forehead close to the knees and the vertex of the head resting on the floor. The drops are instilled and the position is held for two minutes.

\section{Methods}

Twenty patients (six male, 14 female, aged 23 to 72 ) were selected because of severe chronic symptoms. All had anterior or posterior purulent nasal discharge, or both. Nine patients also had facial pain and 12 had nasal blockage. Betamethasone with neomycin nasal drops were prescribed

Address for reprint requests: Dr $\mathbf{R}$ Wilson, Host Defence Unit, Cardiothoracic Institute, London SW3 6HP.

Accepted 9 December 1986 as two drops instilled into each nostril twice daily for two weeks. The patients were randomised to take the drops in either the HB or the HDF position. The nursing sister explained the appropriate position with the aid of a diagram, and a symptom diary card was completed daily by each patient.

The following assessment was performed before and at the end of treatment by medical staff unaware of the position adopted by the patient. A nasal swab was taken for bacterial culture, sinus radiographs were performed, and nasal mucociliary clearance time was measured by the modified saccharin method. ${ }^{3}$ Nasal airways resistance was measured by active anterior rhinomanometry (Mercury NRS rhinomanometer interfaced to a BBC type B microcomputer), in which the flow $(\mathrm{ml} / \mathrm{s})$ required to achieve $150 \mathrm{~Pa}(1.1 \mathrm{~mm}$ $\mathrm{Hg}$ ) of pressure on inspiration and expiration in each nostril was recorded. Patients were interviewed and examined by a surgeon.

In the analysis of the diary cards, a definite response to treatment was judged to have occurred if all symptoms cleared, a partial response if only some features improved, and no response if the patient reported no change. Rhinomanometric indices were considered to have improved if a blocked nostril cleared or if the sum of the pretreatment inspiratory and expiratory nasal airways resistance of each nostril was reduced by $50 \%$. A nasal mucociliary clearance time of more than $\mathbf{3 0}$ minutes was considered abnormal and an improvement was held to have occurred if this was shortened by 20 minutes or more. Improved bacteriological

Response of symptoms and abnormalities found in investigations to treatment in the two positions

\begin{tabular}{|c|c|c|c|c|}
\hline & \multicolumn{2}{|c|}{ Head down and forwards position (No of patients) } & \multicolumn{2}{|c|}{ Head backwards position (No of patients) } \\
\hline & $\begin{array}{l}\text { With symptom or } \\
\text { abnormality }\end{array}$ & With improvement & $\begin{array}{l}\text { With symptom } \\
\text { or abnormality }\end{array}$ & With improvement \\
\hline \multicolumn{5}{|l|}{ Symptoms } \\
\hline Discharge* & 10 & 8 & 10 & 3 \\
\hline Blockage† & 8 & 5 & 4 & 0 \\
\hline Facial pain & 3 & 2 & 6 & 0 \\
\hline \multicolumn{5}{|l|}{$\begin{array}{l}\text { Abnormality in } \\
\text { Investigations }\end{array}$} \\
\hline Sinus radiographs & 9 & 5 & 9 & 2 \\
\hline Bacteriology & 5 & 4 & 4 & 2 \\
\hline Rhinomanometry & 1 & 1 & 2 & 0 \\
\hline Nasal mucociliary clearance & 7 & 4 & 5 & 1 \\
\hline \multicolumn{5}{|l|}{ Intranasal appearance } \\
\hline on examination & 7 & 2 & 8 & 1 \\
\hline
\end{tabular}

${ }^{*} \mathrm{p}<0.07\left(\chi^{2}\right.$ test, $\left.1 \mathrm{df}\right)$ with respect to numbers of patients responding to treatment in the two different positions.

tp $<0.2\left(\chi^{2}\right.$ test, $\left.1 \mathrm{df}\right)$ with respect to numbers of patients responding to treatment in the two different positions. 
results were defined as eradication of a pathogenic organism isolated before treatment. The resolution of intranasal mucosal inflammation or hypertrophy was assessed by an ear, nose, and throat surgeon.

\section{Results}

The two groups of patients were of similar mean age (HB 49, HDF 54 years), and had similar symptoms and results before treatment (table). Analysis of diary cards showed that patients using the HDF position responded significantly better to treatment than those using the HB position $\left(\chi^{2}\right.$ test, $p<0.025,2$ degrees of freedom). In the HDF position seven patients responded, one partially responded, and two did not respond. In the HB position one patient responded, two partially responded and seven did not respond. The results in terms of individual symptoms, and also results of investigations, are shown in the table; in each case patients using the HDF position responded more favourably.

\section{Discussion}

There is a large inflammatory component to mucopurulent sinusitis, which may contribute to chronic symptoms by reducing drainage and mucociliary clearance. The maxillary sinus is most frequently affected. Its ostium is situated high above the floor of the antrum, so that in the standing or sitting position clearance depends solely on mucociliary transport, which may be compromised during infection, leading to accumulation of bacteria and inflammatory secretions. ${ }^{4}$ We therefore used a preparation combining a broad spectrum antibiotic with an anti-inflammatory agent.
Because the efficacy of this topical preparation may $\overrightarrow{\mathrm{b}}$ reduced by poor distribution within the nose and paranasat sinuses, ${ }^{5}$ we addressed the question of the most favourab position for administration of the drops and showed that bo adopting the HDF position a good response to topical med ication can be achieved in patients with chron品 mucopurulent rhinosinusitis. The poor response of the $\mathrm{H}$ \& group may reflect the overall severity of disease in the patients studied, making it mandatory to maximise efficiency of drug delivery to the nasal and paranasal sinus mucosa ta achieve the desired response.

RW was supported by Janssen Pharmaceuticals Ltd, DA by Fisons PLC, and KLC by Boehringer Ingelheim.

References

1 Moffet AJ. Postural instillation. A method of inducing local and esthesia in the nose. J Laryng Otol 1941;56:429-36.

2 Chalton R, Mackay I, Wilson R, Cole P. Double-blind placebocontrolled trial of betamethasone nasal drops for nasal polye posis. Br Med J 1985;291:788.

3 Stanley PJ, MacWilliam L, Greenstone MA, Mackay IS, Cole PJ. Efficacy of a saccharin test for screening to detect abnorm mucociliary clearance. Br J Dis Chest 1984;78:62-5.

4 Draf W. Endoscopy anatomy and pathology of the paranas sinuses. In: Endoscopy of the paranasal sinuses. Berlin: Spring Verlag, 1983:28-43.

5 Mygind N. Topical steroid treatment for allergic rhinitis an allied conditions. Clin Otolaryngol 1982;7:343-52. 